\title{
Damping of vertical and horizontal transverse vibrations in the bridge span structures
}

\author{
Darya Provornaya ${ }^{1, *}$, Sergey Glushkov ${ }^{1}$, and Leonid Solovyev ${ }^{1}$ \\ ${ }^{1}$ Siberian Transport University, 630049 Novosibirsk, Russia
}

\begin{abstract}
The paper considers the issues of vibration isolation of railway bridge units on high-speed lines and seismic protection using dynamic vibration dampers. The purpose of the research is to justify the efficiency of damping the dynamic vibrations of the bridge supports with seismic insulating support parts. The research methodology involves building mathematical models of the systems under consideration and their numerical analysis. The methods of structural mechanics and dynamics of structures were used for solving the assigned tasks. The basic mathematical dependences of the vibration system with two seismic masses were developed. The rolling stock was represented by concentrated forces moving along the span structure. As a result, a new scheme for dynamic damping of vibration of the bridge supports was proposed according to which the span structure used as the dynamic vibration damper has an additional fastening on a rigid abutment.
\end{abstract}

\section{Introduction}

The design of railway bridges on high-speed lines and bridges in seismic areas shall be carried out with the account of special requirements to the dynamic characteristics of span structures and supports [1,2]. Such requirements may be deemed critical when choosing the structural solutions. But if for the bridges on high-speed lines the tasks to be solved relate to the prevention of lifting-off (unloading) of truck wheels of the rolling stock and travelling comfort, the main problems concerning the issues on seismic protection relate to prevention of throwing down the span structures from supports and elimination of occurrence of excessive forces in the support sections. In other cases, the requirements of the design standards [3] to dynamic characteristics of the span structures are not critical and are usually ensured.

According to recent research all seismic isolation systems are divided into stationary and adaptive ones [6]. Stationary systems retain their elastic and damping characteristics in case of vibration, and the adaptive systems irreversibly change their parameters thus adapting to the loading program (seismic impact). Stationary seismic isolation systems may be subdivided into systems with and without restoring force. The last type of seismic isolation is arranged by the use of a seismic insulating sliding belt (seismic belt). In such systems load exceeding the frictional force in the seismic belt cannot be transferred to the seismic insulating part of the structure. Designs of seismic insulating belts were proposed

\footnotetext{
${ }^{*}$ Corresponding author: molokovada@gmail.com
} 
by many experts, but they were studied in more details in the works of L.S. Kilimnik, V.P. Chudnetsov and L.A. Soldatova [16]. A new method of seismic isolation is considered on the basis of the previous studies.

Dynamic calculations of bridges on the high-speed lines require consideration of the mechanical vibration system such as "bridge-moving train" having energy dissipation properties. Repeated loads from the oncoming trucks of a moving train cause the forced vibrations of the span structures in a certain speed range. Vibrations with frequencies close enough to the natural structure vibration frequencies may cause resonance effect. The resonance effect for high-speed lines is a much greater problem than the movement of trains with normal speeds (up to $160-200 \mathrm{~km} / \mathrm{h}$ ) because of the danger of losing contact between the wheel and the rail [8].

For the purpose of eliminating the resonance in the existing design practice, the method of adjustment of the span structure mass is applied upwards (in comparison with the solutions providing only the strength of the structures). This entails an increase in expenses both for the span structure, and for supports and foundations, as well as the complication of conditions of installation of structures [4]. The use of dynamic vibration dampers allows us to achieve compliance with the requirements for bridges on the high-speed lines in terms of safety of operation even with the use of span structures of standard design solutions [5].

The scientific problem is that with regard to calculation and design of all kinds of structures for seismic regions the calculation of seismic resistance of bridges falls back the calculations of joint seismic resistance because the demolition of bridges by percentage takes not the first place on the total scale of destructions after the earthquake [7]. Existing recommendations on the assigning of calculation models for bridges when calculating the seismic impacts do not provide for the basis for multilevel design. The system created during the last 10 years includes the updated systems of anti-seismic reinforcement of bridges based on the principles of seismic isolation and seismic damping [16].

The purpose of the research is to justify the efficiency of damping the dynamic vibrations of the bridge supports with seismic insulating support parts. The scientific novelty of the research results includes:

1. use of vibration dampers of a new type for improvement of operational characteristics of the bridge span structures;

2. study of vibrations of support assemblies in span structures;

3. development of the span structure design concept with dynamic vibration damper considered in this research work.

\section{Mathematical research model}

Let us consider a beam of a span structure which is exposed to rectilinear vibrations under the influence of a harmonic force with amplitude $F_{0}$ and frequency $\omega$. Assume that $x_{0}(t)$ is the displacement of the span structure in the horizontal or vertical plane, and $x_{1}(t)$ is the displacement of damper.

On the basis of the obtained calculation model, we are going to develop a mathematical model for it, which may most fully describe the behaviour of the system: span structure beam - dynamic vibration damper - support. Differential equations of the system movement can be written in the form as follows:

$$
\left\{\begin{array}{l}
m_{0} \ddot{x}_{0}+\left(C_{0}+C_{1}\right) x_{0}-C_{1} x_{1}+\left(h_{0}+h_{1}\right) \dot{x}_{0}-h_{1} \dot{x}_{1}=F \sin \omega t \\
m_{1} \ddot{x}_{1}-C_{1} x_{0}+\left(C_{1}+C_{2}\right) x_{1}+\left(h_{1}+h_{2}\right) \dot{x}_{1}-h_{1} \dot{x}_{0}=0 .
\end{array}\right.
$$

The system is solved using the method of complex amplitudes. For this purpose let us 
write down the system of equations in the same way as (1) thus denoting in the left part $x_{0}$ and $x_{1}$ through $y_{0}$ and $y_{1}$ respectively, and specifying $F_{0} \cos$ in the right part. The initial system (1) is added to the resulting system of equations multiplied by $i=\sqrt{-1}$, and we obtain a system of equations relative to the complex variables $z_{0}=i x_{0}+y_{0}$ и $z_{1}=i x_{1}+y_{1}$ :

$$
\left\{\begin{array}{c}
m_{0} \ddot{z}_{0}+\left(C_{0}+C_{1}\right) z_{0}-C_{1} z_{1}+\left(h_{0}+h_{1}\right) \dot{z}_{0}-h_{1} \dot{z}_{1}=F e^{i \omega t} \\
m_{1} \ddot{z}_{1}-C_{1} z_{0}+\left(C_{1}+C_{2}\right) z_{1}+\left(h_{1}+h_{2}\right) \dot{z}_{1}-h_{1} \dot{z}_{0}=0 .
\end{array}\right.
$$

The system (2) is solved as follows:

$$
z_{0}(t)=A_{0} e^{i \omega t} ; \quad z_{1}(t)=A_{1} e^{i \omega t}
$$

Taking into account the expression (3) we obtain from (2) a system of linear algebraic equations for the complex amplitudes $A_{0}$ and $A_{1}$ :

$$
\left\{\begin{array}{l}
{\left[-m_{0} \omega^{2}+C_{0}+C_{1}+i\left(h_{0}+h\right)_{1} \omega\right] A_{0}-\left[C_{1}+i h_{1} \omega\right] A_{1}=F} \\
{\left[-m_{1} \omega_{1}^{2}+C_{1}+C_{2}+i\left(h_{1}+h_{2}\right) \omega\right] A_{0}-\left[C_{1}+i h_{1} \omega\right] A_{0}=0}
\end{array}\right.
$$

or in non-dimensional form

$$
\left\{\begin{array}{l}
{\left[1-\Omega^{2}+i q_{0} \Omega\right] \bar{A}_{0}-\left[i q_{01} \Omega+\lambda\right] \bar{A}_{1}=1} \\
{\left[\mu\left(v^{2}-\Omega^{2}\right)+i q_{1} v \mu \Omega\right] \bar{A}_{1}-\left[i q_{01} \Omega+\lambda\right] \bar{A}_{0}=0}
\end{array}\right.
$$

where $\mu=m_{1} / m_{0}$ is the mass ratio of the damper and the beam; $v^{2}=\omega_{1}^{2} / \omega_{0}^{2}-$ damper adjustment; $\omega_{0}=\sqrt{\left(C_{0}+C_{1}\right) / m_{0}}$ - natural frequency of the span structure beam; $\omega_{1}=\sqrt{\left(C_{1}+C_{2}\right) / m_{1}}-$ partial frequency of the damper; $=/ 0-$ non-dimensional excitation frequency; $q_{0}=2\left(h_{0}+h_{1}\right) / h_{0 \text { кр }}, q_{01}=2 h_{1} / h_{0 \text { кр }}, q_{1}=2\left(h_{1}+h_{2}\right) / h_{1 к р}$ non-dimensional ratios of resilient friction; $\bar{A}_{0}=A_{0} / A_{0 C}, \bar{A}_{1}=A_{1} / A_{0 C}$ - nondimensional amplitudes of vibrations of the span structure beam and the damper, respectively; $A_{0 C}=F_{0} / C_{0}$ - conditionally static movement of the span beam during passage of the travelling load.

Since the forced vibrations are considered, it is sufficient to determine only the amplitudes of these vibrations, that is, the modules of complex amplitudes. When solving the system of equations (5), we obtain

$$
\begin{gathered}
\left|\bar{A}_{0}\right|=\sqrt{\frac{\mu\left(\mathrm{v}^{2}-\Omega^{2}\right)^{2}+\left(q_{1} v \mu \Omega\right)^{2}}{A^{2}+i B^{2}}}, \\
\left|\bar{A}_{1}\right|=\sqrt{\frac{\left(q_{01} \Omega\right)^{2}+\lambda^{2}}{A^{2}+i B^{2}}},
\end{gathered}
$$

where $\mathrm{A}$ is the real part and $\mathrm{B}$ is imaginary part defined by formulas

$$
A=\mu \Omega^{4}-\Omega^{2}\left[\mu\left(1++q_{0} q_{1} \mathrm{v}\right)-q_{0}^{2}\right]+\mu v^{2}-\lambda^{2},
$$




$$
B=-\mu \Omega^{3}\left(q_{0}+q_{1} \mathrm{v}\right)+\Omega\left(q_{0} \mu \mathrm{v}^{2}+q_{1} \mu \mathrm{v}-q_{01} \lambda^{2}\right) .
$$

\section{Solution of the research model}

Expressions (6) and (7) are equations for the determination of vibration amplitudes on the support of the span structure and the dynamic damper, respectively. Analysis of expression (6) allows us to conclude that, for any type of adjustment of the damper, the amplitude of the span structure beam does not go to zero. But if $q_{1}=0$ (there is no damping in the damper), then $|\bar{A}|=0$ with any $v=\Omega\left(\omega_{1}=\omega\right)$. Consequently, the vertical and horizontal vibrations of the span structure beam will be damped by the additional mass at a partial frequency of the damper equal to the excitation frequency. The vibration amplitude of the damper itself differs from zero and finite in this case.

According to the classical theory [15], there are three ways to prevent the vibrations and oscillations such as: reduction of the level of vibration in the source, reduction of its level along the path of extension, and change of the resonance properties of the protected objects. One of the effective methods for reducing vibrations of span structures is the creation of passive multi-resonance dynamic vibration dampers. Dynamic damping of vibrations involves the adding to the main vibrating mass of the additional mass which forms a certain part of the main mass.

Depending on the properties of connections, there are dynamic vibration dampers [9, 10] having a form of an additional mass applied to the mass of the main structure by means of an elastic element or pendulum scheme. The additional mass is applied to the mass of the main structure using the viscous or friction elements, namely, the dampers (impact absorbers). Also the additional mass may be applied to the main structure mass by means of resilient and viscous elements. Depending on the amount of additional mass the dynamic vibration damper may be [11] of a small mass (the damper mass is $10 \%$ of the mass of the structure); equal (commensurate) mass (the damper mass is equal to the mass of the structure); large mass, when the damper mas exceeds the mass of the structure by two or more times.

The dynamic vibration damper of small mass is effective for adjusting the vibrations of span structures according to the conditions for passing high-speed traffic. Taking into account the complex spectrum of the impact of moveable loads on the bridges, it is advisable to create the unified passive dynamic vibration dampers, which can be set for elimination of any resonance effects. The dynamic vibration damper of small mass used for damping the vibration in case of seismic impacts has its disadvantages since such a damper is very sensitive to setting and there can be no damping effect in the event of relatively small deviations caused by inaccuracies in mounting [14].

A device for damping vertical and horizontal transverse vibrations can be used as a dynamic vibration damper of small mass. Such device consists of a supporting elastic element in the form of a coil spring (Fig. 1) $[12,13]$. Such a design can be installed either directly on the span structure (as applicable to reference to the high-speed lines), or between the support and the span structure beam (for seismic impacts). In the latter case, the rigidity of the spring 1 will mainly be determined according to the requirements for vertical displacement of the path. 


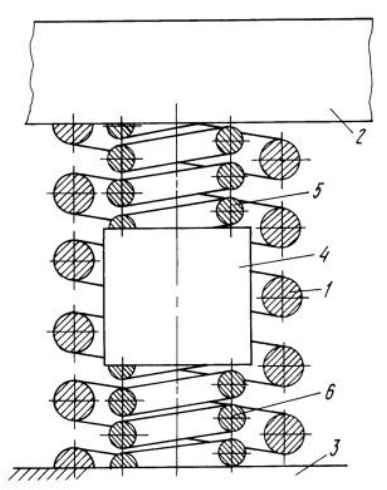

$\mathrm{a}$

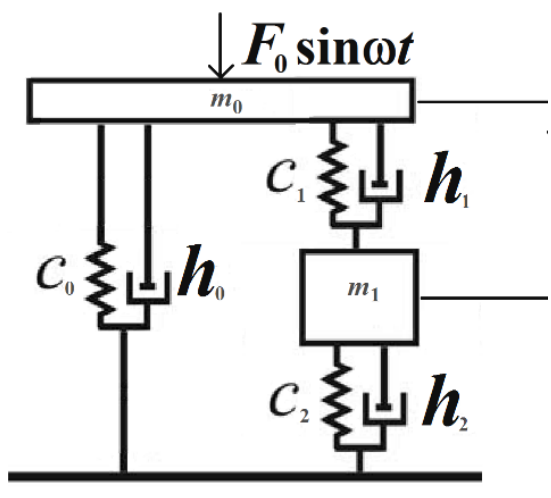

b

Fig. 1. Dynamic vibration damper (a) and its design scheme (b) $\mathrm{C} 0$ - stiffness of the main carrier spring; $\mathrm{C} 1$ and $\mathrm{C} 2$ - the stiffness of the main and additional springs of the absorber, respectively; h1, $\mathrm{h} 2, \mathrm{~h} 3$ - damping factors; $\mathrm{m} 0, \mathrm{~m} 1$ - mass of beam and dynamic absorber, respectively.

The device under consideration is a supporting elastic member 1 in the form of a coil spring installed between the supports 2 and 3 and a dynamic damper in the form of a coaxially installed inertial mass connected to the supports by the springs 5 and 6 . Such installation of the inertial masses of the damper enables to change the interaction of the support and the span structure at operating frequencies of the span structure beam.

It is possible to change this interaction by compensating the periodic forces and moments transmitted by the supporting elastic elements, forces and moments of the opposite direction from the inertial masses vibrating in the opposite direction. It should be noted that if mass 4 is taken as the mass of a span structure, then such a damper becomes a damper of equal (commensurate) mass and can be effectively used for seismic protection in this form.

\section{Results}

On the basis of the expressions obtained a support part enabling the use of the span structure mass as a dynamic vibration damper (Fig. 2) was constructed. As for the conditional initial data (a beam of pre-stressed reinforced concrete, load C14, estimated seismicity in 9, maximum permissible vertical movements according to the railway operation rules), the spring parameters were selected in accordance with GOST 13765-86. The same stiffness was assigned for all springs for uniform activation. 


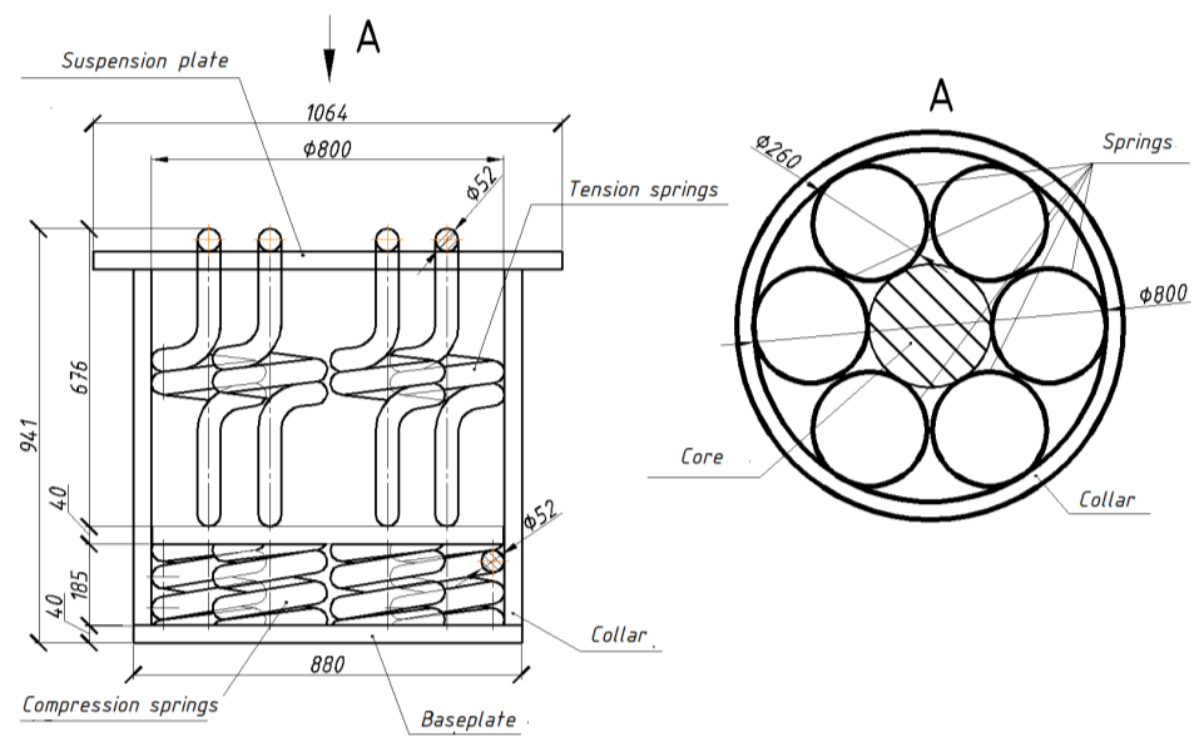

Fig. 2. Schematic diagram of the support part.

The developed support part does not exceed the overall dimensions of the existing seismic insulating support parts, and can be placed both above the bearing block (pier cap) of the supports, and in a special niche in the pinnacle. Such a support part is serviceable and, if necessary, can be replaced entirely. It works on the principle of the device, considered in Figure 1.

\section{Conclusion}

The support part obtained according to the results of calculations makes it possible to change the interaction of the support and the span structure at operating frequencies of the span structure beam. It will solve the problem of lack of modern calculations and recommendations for designing seismic isolation of bridges.

It is possible to change this interaction by compensating the periodic forces and moments transmitted by the supporting elastic elements, forces and moments of the opposite direction from the inertial masses vibrating in the opposite direction. The developed support part consists of compression and extension springs working together for bearing both vertical and horizontal loads arising from permanent, temporary and seismic impacts. In addition to the main task of bearing vertical and horizontal loads, such a support part is able to return the span structure to the initial position after having been exposed to the seismic impact. Also, it eliminated the resonance that does not increase the expenses both for the span structure, and for supports and foundations, and does not complicate the conditions of installation of structures. The use of such supports allows us to achieve compliance with the requirements for bridges on the high-speed lines in terms of traffic safety even with the use of span structures of standard design solutions.

\section{References}

1. STU-4. Engineering structures of Moscow-Kazan section of high-speed railway track 
Moscow - Kazan - Yekaterinburg. Technical regulations and requirements todesign and construction (St.-Petersburg Publ., 2016). (in Russian)

2. SP 14.13330.2011. Construction in seismic regions. Revised edition of SNiP II-7-81* (Moscow, 2011). (in Russian)

3. SP 35.13330-2011. Bridges and pipes. Revised edition of SNiP 2.05.03-84* (Moscow, 2011). (in Russian)

4. A.V. Romanov, E.I. Shehtman, Bulletin of research results, 3(8), 48-53 (2013). (in Russian)

5. L. Fryba, Dynamics of Railway Bridges (Thomas Telford, London, 1996).

6. V.M. Kruglov, Naukovedenie, Vol. 5 (24), (2014). (in Russian)

7. L.K. Dyachenko, Author's abstract of candidate of science thesis (Saint-Petersburg, 2017). (in Russian)

8. Y.B. Yang, Vehicle-bridge interaction dynamics with applications to high-speed railway (World Scientific, 2004).

9. A.L. Zakora, Science and transport progress. Bulletin of Dnipropetrovsk National University of Railway Transport named after Academician V. Lazaryan, 6, 118-123 (2005). (in Russian)

10. U.Z. Shermuhamedov, I.O. Kuznetsova, Science and transport progress. Bulletin of Dnipropetrovsk National University of Railway Transport named after Academician V. Lazaryan, 41, 175-180 (2012). (in Russian)

11. S.P. Glushkov, A.M. Baranovsky, RU Patent 2082907 (1997). (in Russian)

12. S.P. Glushkov, Author's abstract of candidate of science thesis (Novosibirsk, 1999). (in Russian)

13. S.P. Glushkov, L.U. Solovyev, N.A. Donets, Vestnik of TSUAB, 4, 27-34 (2011). (in Russian)

14. V. Hajbin'. Author's abstract of candidate of science thesis (Moscow, 2010). (in Russian)

15. U.Z. Shermuhamedov, Author's abstract of candidate of science thesis (SaintPetersburg, 2010). (in Russian)

16. T.V. Sukonnikova, Author's abstract of candidate of science thesis (Saint-Petersburg, 2017). (in Russian) 